\title{
Analysis Of Breastfeeding Patterns Of Exclusive Breastfeeding For Mothers Carried Out Early Breastfeeding Initiation And The Factors That Influence It In The Working Area Of The Ngantang Public Health Center
}

\author{
Husnul Khotimah ${ }^{1}$, Sandu Siyoto ${ }^{2}$, \\ Siti Farida Noor Laily ${ }^{3}$ \\ ${ }^{1}$ Students of the Master Program in \\ Public Health, Strada Indonesia \\ Health Sciences Institute \\ ${ }^{2}$ Lecturer in the Master Program in \\ Public Health, Strada Indonesia \\ Health Sciences Institute \\ ${ }^{3}$ Lecturer in the Master Program \\ in Public Health, Strada \\ Indonesia Health Sciences \\ Institute \\ Email:
}

husnul2014khotimah@gmail.com

Received: October 5, 2020

Accepted : November 27, 2020

Published : November 30, 2020

\section{ABSTRACT}

Early Breastfeeding Initiation a process of letting the baby's skin contact with the mother's skin for 1 hour, until the baby can suckle itself, Implementation of Early Breastfeeding Initiation, followed by exclusive breastfeeding, can reduce infant mortality, while the baby can grow more optimally and with quality. The low achievement of exclusive breastfeeding in Malang, especially in Puskesmas Ngantang, which is $49.1 \%$ is influenced by many factors. This study aims to analyze the influence, Early Breastfeeding Initiation, Husband Support, Mother's Live Status, and Mother's Motivation towards Exclusive Breastfeeding Breastfeeding Patterns, in the working area of Ngantang Health Center in Malang Regency. This research uses quantitative analysis, using retrospective observation, and the Random sampling technique. Respondents were 151 nursing mothers whose babies were 6-12 months old. The location of the study was conducted in 13 villages in the Work Area of the Ngantang Community Health Center, in February 2020. Results of the analysis of Early Breastfeeding Initiation $(p=0.352)$, Maternal Residence Status ( $\mathrm{p}=0.378)$, Husband Support $(\mathrm{p}=0.872)$, had no significant effect about breastfeeding, only maternal motivation is influential $(\mathrm{p}=0.026)$ Exclusive breastfeeding is indeed very difficult to do, many factors are needed for achieving exclusive breastfeeding, support from all parties is needed especially, great motivation from mothers to provide exclusive breastfeeding.

Keywords: exclusive breastfeeding, early breastfeeding initiation, mother's motivation

This is an open-acces article distributed under the terms of the Creative Commons Attribution-ShareAlike 4.0 International License.

\section{INTRODUCTION}

The importance of giving breast milk to babies is reflected in the recommendations of the World Health Organization (WHO) which urges every mother to provide exclusive breastfeeding until the baby is 6 months old. According to UNICEF, children who are exclusively breastfed are 14 times more likely to survive the first 6 months of life than children who are not breastfed.

Breastfeeding from the first day of life can reduce the risk of newborn death by up to $45 \%$. Research conducted in Kilimanjaro Tanzania shows that EFB (Exclusive Breastfeeding) is effective in preventing under-five mortality by up to $13-15 \%$ coverage (Noer, Nuraeni 2019).

For IMD Achievements, in 2018, nationally, the percentage of newborns who received IMD was $71.17 \%$. This figure has exceeded the 2018 Strategic Plan target of $47.0 \%$. Province. Meanwhile, 
in East Java Province, the IMD achievement was lower than the national achievement, which was 67.66. (Indonesian Ministry of Health, 2019) Meanwhile, the IMD achievements in Malang Regency the IMD achievement was $62.47 \%$ for the Puskesmas Ngantang the IMD achievement in 2018 was 64.3\% (Puskesmas Performance Achievement Data in 2018)

The low Achievement of Exclusive Breastfeeding in the Ngantang Community Health Center is influenced by many factors, one of which is the support of the immediate family, especially the husband and other nuclear families, the mother or mother-in-law giving exclusive breastfeeding. The full support of a husband to his wife in the process of breastfeeding his baby increases the success of exclusive breastfeeding. The role of breastfeeding father is something that must be done by fathers to support exclusive breastfeeding, so that the process of breastfeeding exclusively by mothers can run successfully (Ariani, 2010).

According to the Director-General of Nutrition and MCH, breastfeeding infants aged 0-6 months is exclusively influenced by support from husbands, families, health workers, the community, and the work environment for breastfeeding mothers (Ministry of Health, 2011).

Based on the results of the Preliminary study we conducted in May 2019, out of 145 mothers who carried out Early Breastfeeding Initiation there were only 60 mothers who succeeded in giving Exclusive Breastfeeding, the rest failed for various reasons and causes, and based on the observations we have made since the last 2 years many mothers which were successfully carried out by IMD failed to provide exclusive breastfeeding. With many mothers failing to provide exclusive breastfeeding when IMD has been carried out, and many reasons and factors that influence the failure of exclusive breastfeeding, mainly due to the lack of support provided by the immediate family, namely husband and mother or mother-in-law. The general objective of this study was to analyze the husband's support factors, mother's residence status, mother's motivation, and early initiation of breastfeeding to influence the exclusive breastfeeding pattern in the work area of Puskesmas Ngantang Malang Regency in 2020.

\section{MATERIALS AND METHODS}

Using quantitative analysis research methods, Retrospective observation (Case-Control) for a history of IMD (Early Initiation of Breastfeeding). Data were collected using a questionnaire selected by random sampling on breastfeeding mothers who have babies aged 6-12 months in the work area of the Ngantang Health Center 2020. Early Initiation of Breastfeeding, Residence Status, Husband Support, and Mother's Motivation as Independent variables. And exclusive breastfeeding as a dependent variable.

The data processed and collected were tested using logistic regression. This research was also conducted with the Research Ethics Commission of the Strada Indonesia Institute of Health Sciences. With the Ethical Submission Decree Number 1642 / KEPK / XI / 2019.

RESULTS (Times New Roman: 11)

Table 1. Cross-tabulation between variables of early initiation of breastfeeding with exclusive breastfeeding pattern

\begin{tabular}{lllllll}
\hline \multirow{2}{*}{ IMD } & \multicolumn{4}{l}{$\begin{array}{l}\text { Exclusive } \\
\text { breastfeeding }\end{array}$} & \multicolumn{4}{l}{ Not Exclusive Asi Total } \\
\cline { 2 - 7 } & $\mathrm{f}(65)$ & $\%(43)$ & $\mathrm{f}(86)$ & $\%(57)$ & $\mathrm{f}(151)$ & $\%(100)$ \\
\hline Yes & 56 & $37.1 \%$ & 68 & $45.0 \%$ & 124 & $82.1 \%$ \\
Not & 9 & $6.0 \%$ & 18 & $11.9 \%$ & 27 & $17.9 \%$ \\
\hline
\end{tabular}

Based on the table, it shows that $124(82.1 \%)$ of respondents who were initiated early breastfeeding, there were only 56 respondents (37.1\%) who provided exclusive breastfeeding. Meanwhile, of the 27 respondents who did not receive IMD, 9 respondents managed to provide exclusive breastfeeding The results of statistical tests obtained $p$-value $=0.352$, it can be concluded that there is no significant effect between early initiation of breastfeeding and the success of exclusive breastfeeding patterns, in the work area of the Ngantang Puskesmas in 2020. 
Table 2. Cross-tabulation between variables of residence status of mothers who breastfed with exclusive breastfeeding patterns

\begin{tabular}{|c|c|c|c|c|c|c|c|}
\hline & \multicolumn{2}{|c|}{$\begin{array}{c}\text { Exclusive } \\
\text { breastfeeding }\end{array}$} & \multicolumn{2}{|c|}{ Not Exclusive Asi } & \multicolumn{2}{|c|}{ Total } \\
\hline & & $f(65)$ & $\%(43)$ & $f(86)$ & $\%(57)$ & $\mathrm{f}(151)$ & $\%(100)$ \\
\hline \multirow{4}{*}{$\begin{array}{l}\text { Residence } \\
\text { Status }\end{array}$} & Live With Husband & 30 & $19.9 \%$ & 29 & $19.2 \%$ & 59 & $39.1 \%$ \\
\hline & $\begin{array}{l}\text { Living with husband } \\
\text { and mother }\end{array}$ & 19 & $12.6 \%$ & 32 & $21.2 \%$ & 51 & $33.8 \%$ \\
\hline & $\begin{array}{l}\text { Live With Husband and } \\
\text { In-Law }\end{array}$ & 14 & $9.3 \%$ & 22 & $14.6 \%$ & 36 & $23.8 \%$ \\
\hline & $\begin{array}{l}\text { Live with husband and } \\
\text { other family/servants }\end{array}$ & 2 & $1.3 \%$ & 3 & $2.0 \%$ & 5 & $3.3 \%$ \\
\hline
\end{tabular}

Based on the table, it shows that of the 59 respondents who live with their husbands, there are $39.1 \%$ of respondents $(19.9 \%)$ who provide exclusive breastfeeding, for breastfeeding mothers who live with their husbands and with biological mothers of 51 respondents (33.8\%), there are 19 Respondents (12.6\%) who were successful in breastfeeding exclusive breastfeeding, while 32 respondents $(21.2 \%)$ were not successful in providing exclusive breastfeeding, while the percentage of success in exclusive breastfeeding, when the mother was breastfeeding, lived with her husband and mother-in-law, out of 36 respondents. (23.8\%) only 14 respondents $(9.3 \%)$ were successful in giving exclusive breastfeeding, while 22 respondents (14.6\%) were not successful in giving exclusive breastfeeding. The last status of residence is a husband with another family, nephew, servant, etc., out of 5 respondents 2 , respondents $(1.3 \%)$ were successful in breastfeeding exclusive breastfeeding and 3 people.

The test results obtained statistical $p=0.378$, it can be concluded that the residence status of breastfeeding mothers has no significant effect on the success of the exclusive breastfeeding pattern, in the work area of the Ngantang Community Health Center in 2020.

Table 3. Cross-tabulation between variables of husband's support with exclusive breastfeeding patterns.

\begin{tabular}{|c|c|c|c|c|c|c|c|}
\hline & & \multicolumn{2}{|c|}{$\begin{array}{c}\text { Exclusive } \\
\text { breastfeeding }\end{array}$} & \multicolumn{2}{|c|}{$\begin{array}{c}\text { Not Exclusive } \\
\text { Asi }\end{array}$} & \multicolumn{2}{|c|}{ Total } \\
\hline & & $\mathrm{f}(65)$ & $\%(43)$ & $f(86)$ & $\%(57)$ & $\mathrm{f}(151)$ & $\begin{array}{c}\% \\
(100) \\
\end{array}$ \\
\hline \multirow[t]{5}{*}{$\begin{array}{c}\text { Husband's } \\
\text { Support }\end{array}$} & Very good & 37 & $24.5 \%$ & 46 & $30.5 \%$ & 83 & $55.0 \%$ \\
\hline & Well & 24 & $15.9 \%$ & 31 & $20.5 \%$ & 55 & $36.4 \%$ \\
\hline & Enough & 3 & $2.0 \%$ & 7 & $4.6 \%$ & 10 & $6.6 \%$ \\
\hline & Less & 1 & $0.7 \%$ & 2 & $1.3 \%$ & 3 & $2.0 \%$ \\
\hline & Very less & 0 & $0.0 \%$ & 0 & $0.0 \%$ & 0 & $0.0 \%$ \\
\hline
\end{tabular}

The table above shows that mothers with very good motivation, 41 respondents $(27.2 \%)$ of 81 respondents (53.6) gave exclusive breastfeeding, while mothers with good motivation were only 24 respondents (15.9) out of 63 respondents who gave Exclusive breastfeeding for breastfeeding mothers with sufficient motivation of 5 respondents (3.3\%), none of whom succeeded in providing exclusive breastfeeding, by looking at the results above and seeing the results of statistical analysis, the results obtained were $p=0.026$, it can be concluded that there is a significant effect. between the high motivation of mothers to breastfeed and the success of exclusive breastfeeding in breastfeeding mothers in the working area of the Ngantang Community Health Center in 2020.

Table 4. Cross-tabulation between variables of motivation for breastfeeding mothers with exclusive breastfeeding patterns. 


\begin{tabular}{|c|c|c|c|c|c|c|c|}
\hline & & \multicolumn{2}{|c|}{ breastfeeding } & \multirow[b]{2}{*}{ f (86) } & \multirow[b]{2}{*}{$\%(57)$} & \multirow[b]{2}{*}{$\mathrm{f}(151)$} & \multirow[b]{2}{*}{$\%(100)$} \\
\hline & & $\mathrm{f}(65)$ & $\%(43)$ & & & & \\
\hline \multirow{5}{*}{$\begin{array}{l}\text { Mother's } \\
\text { Motivation }\end{array}$} & Very good & 41 & $27.2 \%$ & 40 & $26.5 \%$ & 81 & $53.6 \%$ \\
\hline & Well & 24 & $15.9 \%$ & 41 & $27.2 \%$ & 65 & $43.0 \%$ \\
\hline & Enough & 0 & $0.0 \%$ & 5 & $3.3 \%$ & 5 & $3.3 \%$ \\
\hline & Less & 0 & $0.0 \%$ & 0 & $0.0 \%$ & 0 & $0.0 \%$ \\
\hline & Very less & 0 & $0.0 \%$ & 0 & $0.0 \%$ & 0 & $0.0 \%$ \\
\hline
\end{tabular}

The table above shows that mothers with very good motivation, 41 respondents $(27.2 \%)$ of 81 respondents (53.6) gave exclusive breastfeeding, while mothers with good motivation were only 24 respondents (15.9) out of 63 respondents who gave Exclusive breastfeeding for breastfeeding mothers with sufficient motivation of 5 respondents (3.3\%), none of whom succeeded in providing exclusive breastfeeding, by looking at the results above and seeing the results of statistical analysis, the results obtained were $\mathrm{p}=0.026$, it can be concluded that there is a significant effect. between the high motivation of mothers to breastfeed and the success of exclusive breastfeeding in breastfeeding mothers in the working area of the Ngantang Community Health Center in 2020.

From the table 5, it can be seen, from the simultaneous testing, it was found that a significant value of 0.097 means that together there is no effect between early breastfeeding, mother's residence status, husband's support, and mother's motivation to breastfeed on the pattern of exclusive breastfeeding or the success of exclusive breastfeeding. From the results of partial testing, it was found that there was only one variable that affected, namely the motivation of breastfeeding mothers. Where when the motivation of breastfeeding mothers is categorized as very good, it will increase the success of exclusive breastfeeding by 0.491 times than those who have less motivation.

Table 5. Logistic Regression Test Results Table

\begin{tabular}{cccc}
\hline Variable & Simultaneous Sig & Sig Parcial & Exp (B \\
\hline Early Initiation of & & 0.352 & \\
Breastfeeding & & 0.378 & \\
Residence Status & 0.097 & 0.872 & \\
Husband's support & & 0.026 & 0.491 \\
The motivation of & & & \\
Breastfeeding Mothers & &
\end{tabular}

\section{DISCUSSION}

\section{IMD (Early Initiation of Breastfeeding) with Exclusive Breastfeeding Pattern}

The results of statistical test analysis for BMI (Early Initiation of Breastfeeding) with Exclusive Breastfeeding Pattern, obtained a value of $p=0.352$, ( $p>0.05$ ) it can be concluded that there is no significant effect between early initiation of breastfeeding and the success of exclusive breastfeeding patterns, in this region. The work of the Ngantang Puskesmas in 2020, this is in line with research conducted by Anna Saudari Azhari, Terry YR and Pristya at RSIA Budi Kemerdekaan Jakarta in 2019, which obtained a value of 0.415 ( $>$ > 0.05), That there is no significant relationship between IMD (Early breastfeeding initiation) by giving exclusive breastfeeding.

Early initiation of breastfeeding is important in stimulating milk production and strengthening the baby's sucking reflex. The initial sucking reflex in babies is strongest in the first few hours after birth and increases the length of time the baby is breastfed. Therefore, early initiation of breastfeeding will be more beneficial for continued breastfeeding than not early initiation of breastfeeding (Vetty and Elmatris, 2011). According to Eddy Tiro, (2009) one of the goals of Early Initiation of Breastfeeding (IMD), namely: Accelerating milk production. Babies who are allowed to breastfeed early will have a more successful chance of exclusive breastfeeding and maintain breastfeeding than those who postpone early breastfeeding (Dr. Utami Rusli (2017), the above is in line with research conducted by Afi Lutfiyati, Universitas Gajah Mada in 2015, Based on the results of bivariate processing, it is known that the $\mathrm{p}$-value $=0.016(95 \% \mathrm{CI}=1.18-3.64)$, this proves that there is a relationship between the implementation of IMD and exclusive breastfeeding. (Luthfiyati Afi, 2015). 
According to the assumption of researchers that with Early Initiation of to breastfeed, babies will get to know breastfeeding faster and babies, especially neonates, will immediately adapt and get used to breastfeeding, because they have succeeded in Early Initiation of Breastfeeding, Babies who breastfeed immediately after birth provide many benefits, one of which is by stimulating them. drainage of breast milk from the mother's breast so that the milk matures and launches milk production in postpartum mothers (Setyowati, 2018). but there are still some for the early days of breastfeeding which are indeed a lot of constraints because usually, the first day to the third day of milk has not come out a lot, initially what comes out is colostrume, and the amount is only a little, this is not a problem because the milk comes out according to the baby's needs,

Another obstacle that is often encountered is, with different breast anatomy in each mother, especially the shape of the nipple that is protruding, some are flat and some is drowned, or there are other anatomical abnormalities, this is following with the results of research conducted by Zulmuawinah, et al from the Muslim University. In Indonesia, there is a significant influence between breast anatomical abnormalities and exclusive breastfeeding.

Babies who are undergoing IMD (Early Initiation of Breastfeeding) have a strong memory for breastfeeding and breastfeeding mothers tend to be happy and have a strong desire and strong motivation to breastfeed their babies because they have formed a stronger bond when the baby is directly placed on the mother's chest and managed to get the nipple and suck for the first time times, and babies who have successfully had IMD, always want to be close to their mother. But according to our years of experience and monitoring when assisting breastfeeding mothers, and when conducting this study, it turns out that exclusive breastfeeding until the age of 6 months is very, very difficult when IMD is seen from the success of breastfeeding until the age of one month the results are very significant. such as research I did in 2017 that there is a significant relationship between BMI and the success of breastfeeding in Early Neonates) 0-7 days. But when the time is added until the age of 6 months (exclusive breastfeeding) it turns out to be insignificant, because many factors influence it, so that there are many failures at months $2,3,4$, and some fail at month 5 .

\section{The residence status of breastfeeding mothers with exclusive breastfeeding patterns}

The results of statistical test analysis for the residence status of breastfeeding mothers with exclusive breastfeeding patterns obtained $\mathrm{p}$-value $=0.378$ ( $\mathrm{p}>0.05$ ) which means there is no significant effect between the residence status of breastfeeding mothers with the success of exclusive breastfeeding. This is not in line with research conducted by Indah Yun Diniaty Rosodi STIKES Nani Hasanudin Makasar, at the Bontomanaru Makassar Health Center in 2018, from the results of the analysis of the Mann Witney test on the characteristics of the residence status of breastfeeding mothers, the value of $p=0.326$, meaning that there is no significant effect between residence status with the success of exclusive breastfeeding is different from the results of research conducted by Tutik Inayah Susilaningsih, at the Samigaluh II Health Center, in 2013, namely mothers who live with in-laws have the highest exclusive breastfeeding coverage, namely, $73 \%$. Compared to breastfeeding mothers who live with biological mothers, who have the lowest breast milk coverage.

Another opinion, like the research, the results of our study show that the mother's residence status does not effect on the success of exclusive breastfeeding, because with whom the mother lives either only with her husband, or, with her husband and mother-in-law, or husband with the mother's biological mother, even with Other siblings, some are successful in exclusive breastfeeding and some are not, many other factors influence the success of exclusive breastfeeding. Although family support, apart from the husband is also very important to support the exclusive breastfeeding pattern.

Family support that has a relationship with exclusive breastfeeding includes information support, instrumental support, emotional support, and recognition (Nurlinawati et al., 2016). The success of exclusive breastfeeding is largely influenced by family, especially husband, parents, relatives, friends, neighbors, and the surrounding environment (Kurniawati and Hargono, 2014). Family support has a greater influence on exclusive breastfeeding in low or middle-income countries (Jolly et al., 2012). The role of the family is very important to increase the practice of exclusive breastfeeding. The biggest family support in the practice of exclusive breastfeeding is that of the husband. The husband can provide emotional support and practical assistance (Kurniawati and Hargono, 2014) 
Family support provided to increase exclusive breastfeeding includes instrumental support in the form of material or financial, this can be seen from the availability of facilities and infrastructure such as meeting the daily needs of mothers and babies. Award support in the form of praise, encouragement, and positive reinforcement given by the family for the mother's actions in exclusive breastfeeding. Support for providing information from families in the form of advice, enlightenment, or the provision of sufficient information regarding exclusive breastfeeding (Nurlinawati et al., 2016).

\section{Husband support with exclusive breastfeeding pattern}

The third factor is the husband's support for the success of exclusive breastfeeding. From the results of the logistic regression statistical test, the value of $p$-value $=0.872,(p>0.05)$, which means that there is no significant effect between husband's support and the success of exclusive breastfeeding. This result is in line with research by Zulmuawinah, Sumsulam, Dan Nuraini Noer, Nursing Study Program, Sulawesi, Faculty of Public Health, Indonesian Muslim University, South Sulawesi, in 2019, the resulting p-value $=0.844$, $(>0.005)$ which means, also research conducted by Dyan (2011), research conducted by Novira Kusumayanti, Triska Susila Nindya, Nutrition SI Study Program, Faculty of Public Health, Airlangga University, there was no significant relationship between husband's support and exclusive breastfeeding $(p=0.058)$. Indeed, statistically, the husband's support does not have a significant effect on exclusive breastfeeding patterns, but the husband's support is very important to help and encourage breastfeeding mothers to breastfeed their babies because breastfeeding has so many challenges and problems that not only the mother can strive for, but also there must be encouragement from close family, especially the husband who is always there near the mother and to support the mother's mind. The relationship between a father and his baby is an important factor in the growth and development of a child. Fathers also need to understand and understand the problems of breastfeeding and breastfeeding so that mothers can breastfeed properly (Roesli, 2008). But husband's support is very important to help and encourage breastfeeding mothers to breastfeed their babies because breastfeeding has so many challenges and problems that the mother cannot only strive for but also encourages close family members, especially husbands who are always around the mother, and to support the mother's mentality.

The relationship between a father and his baby is an important factor in the growth and development of a child. Fathers also need to understand and understand the problems of breastfeeding and breastfeeding so that mothers can breastfeed properly (Roesli, 2008). But husband's support is very important to help and encourage breastfeeding mothers to breastfeed their babies because breastfeeding has so many challenges and problems that not only can be fought for by mothers but also there must be encouragement from close family, especially husbands who are always around the mother and to support the mother's mentality. The relationship between a father and his baby is an important factor in the growth and development of a child. Fathers also need to understand and understand the problems of breastfeeding and breastfeeding so that mothers can breastfeed properly (Roesli, 2008). The relationship between a father and his baby is an important factor in the growth and development of a child. Fathers also need to understand and understand the problems of breastfeeding and breastfeeding so that mothers can breastfeed properly (Roesli, 2008). The relationship between a father and his baby is an important factor in the growth and development of a child. Fathers also need to understand and understand the problems of breastfeeding and breastfeeding so that mothers can breastfeed properly (Roesli, 2008).

Husbands who understand and understand the benefits of breastfeeding will help mothers take care of the baby, including changing diapers, bathing babies, and giving babies massages. While mothers, try to focus on increasing providing additional formula milk because birth mothers or mothers-in-law think (especially mothers who give birth for the first time) that mothers still do not have experience about baby care and have not to experience about giving the best food for babies, while mothers feel that they are experienced. it must be according to the direction of the biological mother or mother-in-law, even though there are some biological mothers or mothers-in-law whose understanding is still wrong, and is not by the understanding or desire of the breastfeeding mother, due to customs or shy attitudes and norms that must always comply with people old.

Other data shows that one respondent was eager to provide exclusive breastfeeding but when she lived with her mother-in-law she could not refuse when her in-laws gave additional formula milk for fear of insufficient breastfeeding or the baby would become fussy. Although there are also a small 
number of biological mothers or mothers-in-law who recommend giving breast milk only, it depends on the knowledge and experience of the biological mother or mother-in-law when breastfeeding. With the above observations, we can conclude that it is recommended for young married mothers to do as much as possible or better when they have children, they live independently with their husbands.

The quality of breast milk is by eating a balanced nutritious diet and adopting a healthy lifestyle (Roesli, 2016). Friedman et al. (2014) explained that the husband's support has four functions, namely informational support, appraisal support, instrumental support, and emotional support. Informational support is that the husband functions as a recipient and disseminator of information about all the information in life. The husband reminds and informs the mother about the information on exclusive breastfeeding.

Instrumental support is a form of husband's support as the provision of material that can provide direct assistance such as giving money, giving goods, food, and services. This form can reduce stress because the mother can directly solve problems related to the material. Emotional support is a form of family or husband support as a place that is comfortable, safe, and peaceful. Helps psychologically stabilize emotions and self-control, therefore the form of support is by providing motivation and a role in listening to all the complaints of the problems he is facing (Friedman, 2014). The husband's support plays a major role in the success of mothers to provide exclusive breastfeeding. The greater the support provided by the husband, the greater the opportunity for mothers to breastfeed their babies. This will affect the smoothness of the reflex for breastfeeding because it is influenced by the feelings and emotions of the mother. Family support is needed for calm, tranquility,

Reeves, et al. (2012) stated that mothers breastfeed because they believe breast milk is healthier for the baby. Husbands are the most influential providers of support. This support system is very important for breastfeeding mothers to make decisions to exclusively breastfeed babies aged 0-6 months. This supports the research conducted by Mazza, et al. (2014), that two categories influence breastfeeding, one of which is primary social influence. Primary networks are characterized by family members and close people. Husbands can play a role in increasing the mother's confidence in breastfeeding, her confidence can increase milk production.

Another supportive opinion from the Director-General of Nutrition and $\mathrm{MCH}$, breastfeeding infants aged 0-6 months is exclusively influenced by support from husbands, families, health workers, the community, and the work environment for breastfeeding mothers (Ministry of Health, 2011). Exclusive breastfeeding for babies is not only the responsibility of the mother. The head of the family, in this case, the husband also has a big responsibility to provide support (Pemprov DKI Jakarta, 2010).

Because the husband is mostly rarely at home because he as the head of the family has to earn a living for the family and usually the husbands come home tired, so the husband usually leaves the exclusive Asi decision to the wife or the mother. Even though some husbands have a lot of time at home, when there are problems with giving breast milk or the mother wants to give formula milk, usually, the husbands allow it, there are one or two husbands who are so big that they want their babies to only be given breast milk, but when there are many hindering factors, finally her husband leaves all decisions to the nursing mother. When there was a respondent whose husband was indifferent because her husband was a laborer who was tired of working all day, she rarely paid attention to Asi for her baby because her thought was only for making a living.

\section{The motivation of mothers with exclusive breastfeeding patterns}

The fourth factor or the last factor we examined was the mother's motivation. From the statistical test results obtained p-value $=0.026(<$ of 0.05$)$, which means that there is a significant effect between the success of exclusive breastfeeding, with the motivation of breastfeeding mothers, according to Mc. Donald, motivation is a change in energy in a person (person) which is marked by the emergence of feelings and reactions to achieve goals. Meanwhile, according to Abraham Maslow, motivation is constant (fixed), never-ending, fluctuating, and complex, and it is mostly a universal characteristic of every activity of an organism. The results of research conducted by Srigati (2016) wrote that achieving exclusive breastfeeding requires knowledge and motivation from a mother. Mothers who have strong knowledge and motivation, then the mother will try to give breast milk only for 6 months to the baby. The mother knows and understands that the benefits that will be received by 
her baby if the baby is exclusively breastfed, so understanding knowledge encourages motivation. In other words, mothers who do not provide exclusive breastfeeding may have insufficient knowledge about the importance of exclusive breastfeeding so that their motivation to provide exclusive breastfeeding is also low.

Research conducted by Srigati (2016), which states that there is a significant relationship between motivation towards exclusive breastfeeding, the higher the respondent's motivation, the higher the respondent's motivation. Meanwhile, research conducted by Heni et al (2015), who conducted research on the motivation of breastfeeding mothers to provide exclusive breastfeeding, showed that only $27.1 \%$ of breastfeeding mothers had high motivation to provide exclusive breastfeeding to their babies. Furthermore, the results of research that are in line with our research are research conducted by Reni Merta Kusuma, Aesti Irwan, from UNJAYA, Yogyakarta (2018), the results of the study found that as many as $64.7 \%$ of breastfeeding mothers in the work area of Puskesmas Tegalrejo Yogyakarta have high motivation, provide exclusive breastfeeding to the baby. Motivation is the basic drive that drives someone to behave. This urge is in someone who moves him to do something by his encouragement (Uno, 2011). Encouragement from within a person can appear and remain consistent in that person also requires support from other parties. Sukmadinata (2007) adds that the motivation process is also formed from the existence of a driving force to the occurrence of behavior directed at achieving a goal. Proverawati and Rahmawati (2012) wrote that motivation can also arise from the support of husbands, parents, mother-in-law, and other families so that exclusive breastfeeding efforts can be successful.

The author's experience directly in the field, exclusive breastfeeding is very difficult to do because of the many obstacles and problems faced, it takes a strong motivation from breastfeeding mothers to achieve the success of exclusive breastfeeding, because when a breastfeeding mother has the high motivation, she will be as strong as possible to fight for exclusive breastfeeding whatever the obstacles they face, she will keep trying, in our research, and from the results of our observations, there is a breastfeeding mother whose husband does not have breastfeeding support, the mother still succeeds in giving exclusive breastfeeding, there are mothers who live with in-laws and grandmothers her husband who wants to give formula milk because his mother has a high desire and motivation for exclusive breastfeeding, then the mother managed to convince her parents-in-law and grandmother to give exclusive breastfeeding.

\section{CONCLUSION}

1. There is no partial effect between husband's support for breastfeeding mothers with exclusive breastfeeding patterns with a significant value of 0.872 , greater than 0.05 .

2. There is no partial effect between the residence status of breastfeeding mothers with exclusive breastfeeding patterns, with a significant value of 0.378 greater than 0.05 .

3. There is a partial influence between the motivation of breastfeeding mothers with exclusive breastfeeding patterns with a significant value of 0.026

4. There is no partial effect between Early Initiation of Breastfeeding and Exclusive Breastfeeding Patterns with a significant value of 0.352 , greater than 0.05 .

5. Simultaneous testing obtained a value, 0.097, which means that together there is no influence between husband's support, mother's residence status, mother's motivation, and early initiation of breastfeeding on exclusive breastfeeding patterns.

Research Recommendations

For Independent Practice Midwives in the work area of the Puskesmas to support and always breastfeeding campaign, starting from ANC examinations, childbirth, and remaining committed to supporting breastfeeding by not partnering with formula milk companies, especially for babies, and always being a reinforcement and accompanying mothers to continue breastfeeding Exclusive breastfeeding, if possible, breastfeeding until the age of 2 years, in every service with breastfeeding mothers.

\section{ACKNOWLEDGMENTS}

Thank you to all respondents who were willing to be sampled in our research. 


\section{CONFLICTS OF INTEREST:}

The author declares that they have no conflict of interest

\section{REFERENCES}

Diani, O, H, Eti, P, P \& Uki, R, B. (2018), Effectiveness Of Health Promotion By Indonesian Breastfeeding Association In Increasing Exclusive Breastfeeding Coverage In Surabaya City, East Java. Journal of Health Promotion and Behavior, vol. 3, no. 1, hh. 1-15.

Euphrates, MW et al. (2015). The effect of lactation educators implementing a telephone-based intervention among low-income Hispanics: A randomized trial. Health Education Journal, 74 (4), pp. 424-441. DOI: 10.1177 / 0017896914542666.

Holman, DJ, and Grimes, MA. (2003). Patterns for the initiation of breastfeeding in humans, American Journal of Human Biology, 15 (6), pp. 765-780. DOI: 10.1002 / ajhb.10219.

Indonesian Ministry of Health. (2019). Indonesia Health Profile 2018 [Indonesia Health Profile2018]. Available: http: //www.depkes.go.id/resources/download/pusdatin/profil-k Healthindonesia/Data-dan-Informasi_Profil-K Health-Indonesia -2018.pdf.

Health, W., Pusat, K. and Mimika, K. (2018). Factors that influence exclusive breastfeeding in the work area. 3, pp. 206-211.

Kusuma, RM, and Irawan, A. (2018). Motivation of Breastfeeding Mothers in Providing Exclusive Breastfeeding at Tegalrejo Health Center Yogyakarta. pp. 49-58.

Kusumayanti, N. and Nindya, TS. (2016). Relationship between Husband's Support and Exclusive Breastfeeding in Rural Areas. pp. 98-106.

Laila, Y, A, S \& Maha, M, A, M. (2015). Pregnant \& Lactating Mothers Attitudes And Practice Of The Ten Steps To Successful Breastfeeding At King Fahd Hospital Of University (KFHU) Khobar, Saudi Arabia: Appraisal Of Baby-Friendly Hospital Initiatives. Journal of Education and Practice, vol. 6, no. 11, hh. 9-18.

Muhlisin, A. (2015). Family Nursing. Yogyakarta: Gosyen Publishing

Maryam, S, Maryam, X, L \& Yuliawati, R. (2018). The Relationship Between Education and Family Support and the Failure of Exclusive Asi. Journal of Health of Studies, vol. 3, no. 2, hh. 79 86.

Mawaddah, S. (2018). The Relationship between Early Initiation of Breastfeeding and Giving Exclusive Breastfeeding for Infants. Journal of Health Info, vol. 16, no.2, pg. 214-225.

Notoadmodjo, Soekidjo. (2017). Health Promotion and Behavioral Science. Jakarta: Rineka Cipta

Noer, Nuraeni, Z. (2019). Predictors of Exclusive Breastfeeding for Breastfeeding Mothers in the Work Area of Puskesmas Mangasa, Makassar City. Article history: Public Health Faculty Received 23 May 2018 Universitas Muslim Indonesia Received in revised form 12 December 2018 Address: Email':, 2 (1), pp. 12-17

Roesli U. (2017). Early Initiation of Breastfeeding Plus Exclusive Breastfeeding. I. Jakarta: Pustaka Bunda. 